\title{
Inspirational Women in Surgery: Dr Samantha Pillay, FRACS (Urologist, South Australia)
}

\author{
Savio George Barreto ${ }^{1,2}$ (i)
}

Accepted: 19 December 2021 / Published online: 12 January 2022

(C) Crown 2022

Dr Samantha Pillay was born in Adelaide, South Australia, the youngest of three girls. Her father, a Malaysian of Sri Lankan ethnicity, met her English mother in Singapore whilst working there as a doctor. At the age of two years, Dr Pillay was diagnosed with congenital hip dysplasia. This relegated her to spending much of her early childhood in hospital undergoing multiple surgical procedures. Her mother, determined to give her as normal a life as possible, installed a hospital bed with traction at home and later managed to find young Samantha an all-girls school that would allow her to attend class in a wheelchair. By the age of six, she had progressed from the wheelchair to crutches with callipers, to finally being able to walk unaided, with restrictions. She remembers getting up stairs in junior school by sitting on her bottom and shuffling up backwards. It wasn't until Dr Pillay was at Adelaide University Medical School that she could finally walk up stairs one step after the other, while holding onto the handrail.

Dr Pillay decided to pursue a career in surgery after spending a period of work experience whilst still a Year 11 student at The Royal Adelaide Hospital in the unit of Dr David Craddock, the Head of Cardiothoracic Surgery. At the age of 16 years, Dr Pillay enrolled in the Adelaide Medical School. It was during her basic surgical training that she chose to specialize in urology. Even at this early stage, she dreamt of setting up a specialized unit to treat urinary incontinence in South Australia-an unmet need at

Savio George Barreto

savio.barreto@flinders.edu.au; savio.barreto@sa.gov.au

1 College of Medicine and Public Health, Flinders University, Adelaide,, South Australia, Australia

2 Division of Surgery and Perioperative Medicine, Department of Surgery, Flinders Medical Centre, Bedford Park, Adelaide, South Australia 5042, Australia the time. She trained under Professor Helen O'Connell, AO in Melbourne, before establishing Continence Matters in Adelaide, in 2002. Professor O'Connell, whom Dr Pillay considers her mentor, was the first female to complete urology training in Australia and a leader in female and functional urology.

From there onwards, Dr Pillay went on to acquire numerous accolades, including being the first female to complete urology training in South Australia and the first urologist in Australia to exclusively sub-specialise in female and functional urology. The latter helped cast the spotlight on incontinence and female urology in the community, as well as the (urology) fraternity. She has worked hard to raise awareness, reduce stigma, provide continence education to the community and health professionals and promote urologists and leaders in the treatment of urinary incontinence. Her most significant contribution as a leader in surgery has been during her tenure as the Chair of the Female Urology Special Advisory Group for the Urological Society of Australia and New Zealand from 2007 to 2013.

Dr Pillay considers herself adept at finding ways to work around her limitations. After being advised not to pursue surgery owing to her inability to stand for prolonged periods, she chose to specialize in a field of surgery where she could perform most of her operating whilst being seated. She reckons. she chose surgery as a profession, in the first place, because it was intense, requiring all of her concentration which helped drown out the noise in her head from her hip pain. Her latest surgery, a hip replacement 4 years ago, has helped completely alleviate her chronic pain offering her, for the first time, an opportunity to focus on a hobby outside of work. This proud single mother of a handsome fourteen-year-old boy is an author. Her first book, 'The No Recipe Cookbook' promotes home cooking and healthy eating to people who do not cook. Her second 


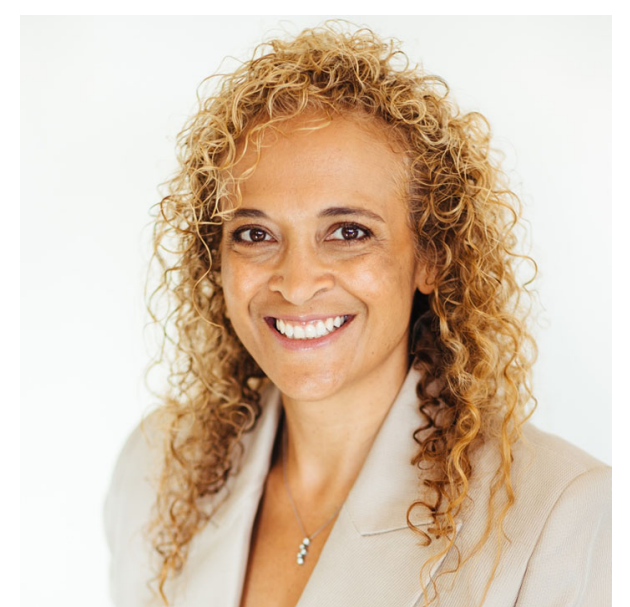

Fig. 1 Dr Samantha Pillay book, entitled 'When I'm a Surgeon' is a children's picture book to challenge career gender stereotypes and inspire young girls to pursue a career in surgery.

Her message to aspiring surgeons is, "Our problems are only a big deal if you make a big deal out of them. Having been born with limitations, I don't let it hold me back, nor do I take what I have for granted. If I can do it, so can you!" (Fig. 1).

Publisher's Note Springer Nature remains neutral with regard to jurisdictional claims in published maps and institutional affiliations. 